\title{
Degradation of fipronil by Stenotrophomonas acidaminiphila isolated from rhizospheric soil of Zea mays
}

\author{
Shivani Uniyal ${ }^{1} \cdot$ Rashmi Paliwal $^{2} \cdot$ R. K. Sharma ${ }^{3} \cdot$ J. P. N. Rai ${ }^{2}$
}

Received: 19 October 2015/Accepted: 24 December 2015/Published online: 8 February 2016

(c) The Author(s) 2016. This article is published with open access at Springerlink.com

\begin{abstract}
Fipronil is a widely used insecticide in agriculture and can cause potential health hazards to non-target soil invertebrates and nearby aquatic systems. In the present study, a fipronil degrading bacterium was isolated from fipronil contaminated soil, i.e. rhizospheric zone of Zea mays. Morphological, biochemical and molecular characterization of strain indicated that it clearly belongs to Stenotrophomonas acidaminiphila (accession no. KJ396942). A three-factor Box-Behnken experimental design combined with response surface modeling was employed to predict the optimum conditions for fipronil degradation. The optimum $\mathrm{pH}$, temperature and total inocula biomass for the degradation of fipronil were $7.5,35{ }^{\circ} \mathrm{C}$ and $0.175 \mathrm{~g} \mathrm{~L}^{-1}$, respectively. The bacterial strain was able to metabolize $25 \mathrm{mg} \mathrm{L}^{-1}$ fipronil with $86.14 \%$ degradation in Dorn's broth medium under optimum conditions. Metabolites formed as a result of fipronil degradation were characterized with gas liquid chromatograph. A novel fipronil degradation pathway was proposed for $S$. acidaminiphila on the basis of metabolites formed. Non-sterilized soil inoculated with $S$. acidaminiphila was found to follow first order kinetics with a rate constant of $0.046 \mathrm{~d}^{-1}$. Fipronil sulfone, sulfide and amide were formed as the metabolites and were degraded below the quantifiable limit after 90 days of
\end{abstract}

Shivani Uniyal

shivi273@gmail.com

1 Department of Environmental science, Swami Ramtirth campus Badshahithaul, Hemwati Nandan Bahuguna Garhwal University, Srinagar Garhwal, Uttarakhand, India

2 Ecotechnology laboratory, Department of Environmental Science, G. B. Pant University of Agriculture and Technology, Pantnagar, India

3 G. B. Pant Institute of Himalayan Environment and Development, Himachal Unit, Mohal-Kullu, Himachal Pradesh, India time period. Given the high fipronil degradation observed in the present study, S. acidaminiphila may have potential for use in bioremediation of fipronil contaminated soils.

Keywords Fipronil - Stenotrophomonas acidaminiphila . Box-Behnken design · Bioremediation · Soil

\section{Introduction}

The widespread use of increasing number of pesticides in agriculture has acquired great importance due to direct and indirect hazards to human health and environment. Globally, about $3 \times 10^{9} \mathrm{~kg}$ of pesticides is applied annually (Pan-UK 2003); however, a large amount of applied pesticides often never reach their intended target due to their degradation, volatilization and leaching, leading to serious ecological problems (Chen et al. 2009; Chevillard et al. 2012). Fipronil [5Amino-3-cyano-1-(2, 6-dichloro 4 trifluoromethylphenyl)-4trifluoromethyl sulfinyl pyrazole] is a phenyl pyrazole insecticide first synthesized by Rhone Poulenc Ag Company (now Bayer Crop Science) in 1987, introduced for use in 1993 and registered in the U.S. in 1996 (Tomlin 2000; Ware 2000; Tingle et al. 2003). It is one of the most persistent, lipophilic and toxic insecticides licensed for use since dieldrin, lindane and DDT (Mohapatra et al. 2010). It controls a broad spectrum of insects such as rice stem borer, leaf folder, cockroaches, mosquitoes, locust, ticks and fleas at both their larval and adult stages (Chanton et al. 2001; Aajoud et al. 2003). Fipronil is a "new generation" insecticide as its mode of action does not follow the common biochemical pathways of classical insecticides such as, pyrethroids (sodium channel blockers), organophosphates, and carbamate (cholinesterase inhibitors) to which some insects have developed resistance (Aajoud et al. 2003). Fipronil elicits its toxicity by blocking the GABA-gated chloride channel in the 
nervous system, resulting in a disruption of neuron signalling and eventually shutdown of the central nervous system (Ecobichon 1996). Fipronil degradation results in the formation of metabolites viz. sulfide, sulfone, amide and desulfinyl $(\mathrm{Gu}-$ nasekara et al. 2007). The half-life of fipronil in soil varies greatly, ranging from 3 days to 7 months.

Bioremediation processes are considered to be cost effective tool for the detoxification of xenobiotics as microbes play an important role in removing toxic substances from the environment (Li et al. 2012; Paliwal et al. 2015a). Microbes have been used in remediation of pesticide contaminated environment (Ramanathan and Lalithakumari 1999; Phugare and Jadhav 2014; Sidhu et al. 2014). Previously, microbial degradation of fipronil was reported in literature (Zhu et al. 2004; Masutti and Mermut 2007; Lin et al. 2008) but very few reports are available on isolation and characterization of specific bacteria, able to degrade fipronil. For instance, Bacillus firmus and Bacillus thuringiensis were found to be competent in the rapid degradation of fipronil (Mandal et al. 2013, 2014). In addition Paracoccus sp. was also found to degrade fipronil (Kumar et al. 2012). Rate of fipronil degradation was reported to affect by many environmental factors including temperature, $\mathrm{pH}$, moisture, formulation, soil composition and biotic factors (Zhu et al. 2004; Masutti and Mermut 2007). For effective biodegradation therefore, it is essential to optimize the process as it makes the technology strong by improving the microbial activities (Prakasham et al. 2005; Paliwal et al. 2015b). However, in none of the previous study, optimization of environmental factors, affecting the rate of fipronil degradation by microbes was conducted.

The aim of this study was therefore to isolate and characterize bacteria, capable of degrading fipronil. Present study reports fipronil degradation by Stenotrophomonas acidaminiphila for the first time. Besides this, response surface methodology (RSM) based on the Box-Behnken design was used to determine the optimum environmental conditions for growth and fipronil degradation by $S$. acidaminiphila. Metabolites formed as a result of degradation were identified and a novel metabolic pathway for fipronil degradation by $S$. acidaminiphila was proposed. The degradation rate of fipronil in soil inoculated with $S$. acidaminiphila, based on the kinetics of degradation was studied. This paper also highlights potential use of pure cultured $S$. acidaminiphila cells for the remediation of fipronil contaminated soils.

\section{Materials and methods}

\section{Chemicals and media}

Technical grade fipronil (Regent $0.3 \%$ G, purity, $97.5 \%$ ) obtained from Bayer Crop Science Ltd, India was used.
Dorn's broth media used for the isolation of bacteria contained the following $\left(\mathrm{g} \mathrm{L}^{-1}\right): \mathrm{Na}_{2} \mathrm{HPO}_{4} \cdot 12 \mathrm{H}_{2} \mathrm{O} 3.0 \mathrm{~g}$, $\mathrm{KH}_{2} \mathrm{PO}_{4} 1.0 \mathrm{~g},\left(\mathrm{NH}_{4}\right) \mathrm{SO}_{4} 1.0 \mathrm{~g}, \mathrm{MgSO}_{4} \cdot 7 \mathrm{H}_{2} \mathrm{O} 10.0 \mathrm{~g}$, $\mathrm{CaCl}_{2} \cdot 2 \mathrm{H}_{2} \mathrm{O} 2.0 \mathrm{~g}, \mathrm{MnSo}_{4} \cdot \mathrm{H}_{2} \mathrm{O} 3.0 \mathrm{~g}, \mathrm{FeSO}_{4} \cdot 7 \mathrm{H}_{2} \mathrm{O} 0.2 \mathrm{~g}$, Ammonium ferric citrate $0.01 \mathrm{~g}$, Yeast extract $0.1 \mathrm{~g}$, Distilled water, pH 7.0 and was sterilized at $121{ }^{\circ} \mathrm{C}$ for $20 \mathrm{~min}$ (Kumar et al. 2012). Dorn's broth media was amended with fipronil $\left(25 \mathrm{mg} \mathrm{L}^{-1}\right)$ as a sole source of carbon and nitrogen. Solid media plates were prepared by adding $2 \%$ agar into above liquid media.

\section{Isolation and identification of fipronil degrading strain}

Soil samples with previous history of fipronil application were collected from the rhizospheric zone $(0-20 \mathrm{~cm})$ of Zea mays plantation, situated at Crop Research Centre of the G.B.P.U.A.T. Pantnagar. Fipronil degrading strains were isolated from soil using the enrichment method of Wang et al. (2013). Strain encoded as S1 was selected on the basis of its highest ability for fipronil degradation and investigated for morphological characteristics and biochemical properties by API $20 \mathrm{NE}$ system (Analytical Profile Index, France). Strain was identified by partial sequencing of $16 \mathrm{~S}$ rRNA. Amplification of the $16 \mathrm{~S}$ rRNA gene of the bacterial isolate was performed with universal bacterial primers $8 \mathrm{f}-1512$ r (Karpouzas et al. 2010). PCR was performed under the following conditions: 30 cycles of denaturation at $94{ }^{\circ} \mathrm{C}(1 \mathrm{~min})$, annealing at $55{ }^{\circ} \mathrm{C}(1 \mathrm{~min})$ and extension at $72{ }^{\circ} \mathrm{C}(1 \mathrm{~min})$. PCR products were purified and sequenced by Chromus Biotech Ltd. Banglore, India. Identification was carried out on the basis of $16 \mathrm{~S}$ rRNA homology between the query and reference sequences available at GenBank using BLAST algorithm of the National Centre for Biotechnology Information (NCBI) database at www.ncbi.nlm.nih.gov/BLAST. Phylogenetic analysis was done using the neighbor-joining method with bootstrap values calculated from 1000 replicate runs, with MEGA 5.1 software.

\section{Optimization of the fipronil degrading conditions}

A Box-Behnken design was performed in order to study the effects of the incubation temperature $\left(25-45^{\circ} \mathrm{C}\right)$, $\mathrm{pH}(5-$ $10)$ and total inocula biomass $\left(0.10-0.25 \mathrm{~g} \mathrm{~L}^{-1}\right)$ on fipronil biodegradation by single-factor experiments. Response surfaces were drawn as a function of two independent variables, while the third was set at a fixed value. Meanwhile, fipronil degradation was investigated to determine the effects of the three factors, namely, incubation temperature, $\mathrm{pH}$ and total inocula biomass. Response surface methodology (RSM) based on the Box-Behnken design was used to investigate the influence of interactive effects 
of the selected parameters on fipronil degradation by strain S1. Box-Behnken design with twelve factorial points and three replicates at the center point was employed in this experiment. A total of 15 runs were used for optimizing the range and levels of chosen variables. Second-order polynomial equation was assumed for predicted response (Eq. 1):

$\beta_{0}+\sum_{i=1}^{k} \beta_{i} X_{i}+\sum_{i=1}^{j-1} \sum_{j=1}^{k} \beta_{i j} X_{i} X_{j}+\sum_{i=1}^{k} \beta_{i i} X_{i}^{2}$

$\mathrm{X}_{i}$ and $\mathrm{X}_{j}$ are variables, $\beta_{o}$ is the constant, $\beta_{i}$ is the linear coefficient, $\beta_{i i}$ is the quadratic coefficient, and $\beta_{i j}$ is the interaction coefficient. Design Expert 8.0.0 (trial version, Stat Ease Inc., Minneapolis, USA) computer program was used for determination of the coefficients of Eq. (1) by regression analysis of the experimental data.

\section{Degradation study}

Logarithmic phase cultures of strain S1 in Dorn's broth media were harvested by centrifugation and washed twice with deionised water. Cell pellets $\left(0.175 \mathrm{~g} \mathrm{~L}^{-1}\right)$ were mixed in sterilized Dorn's broth media, and maintained at approximately 1.5 optical densities at $600 \mathrm{~nm}$ with $25 \mathrm{mg} \mathrm{L}^{-1}$ of fipronil as a sole source of carbon and energy. UV-VIS Spectrophotometer (Varian 50 Bio, USA) was employed for monitoring cell growth. Bacterial cultures were incubated at $35^{\circ} \mathrm{C}, \mathrm{pH} 7.5$ and $120 \mathrm{rpm}$ on a rotary shaker. Samples were collected from the cultures at an interval of 14 days. $5 \mathrm{~mL}$ of samples were centrifuged at $12,000 \mathrm{~g}$ for $10 \mathrm{~min}$, extracted with hexane $(30 \mathrm{~mL})$. Control flask, without culture was also maintained at the same condition. All of the degradation experiments were performed in triplicates. Samples were analyzed by gas liquid chromatograph (GLC) to evaluate residual concentration of fipronil and its metabolites.

\section{Fipronil degradation in soil inoculated with strain S1}

Fipronil degradation by strain S1 was performed in sandy loam soil samples having $\mathrm{pH} 7.2$, organic carbon $0.78 \%$, available $\mathrm{N} 196.75 \mathrm{~kg} \mathrm{ha}^{-1}$, available P $18.24 \mathrm{~kg} \mathrm{ha}^{-1}$ and available $\mathrm{K} 162.37 \mathrm{~kg} \mathrm{ha}^{-1}$. Fipronil degradation study was performed in two different conditions viz. non-sterilized soil without inoculation (control) and non-sterilized soil inoculated with strain S1. Soil samples were fortified with fipronil at the rate of $50 \mathrm{mg} \mathrm{kg}^{-1}$ and then inoculated along with $45 \times 10^{7}$ microbe cells. Each treatment was replicated thrice. Soil samples were incubated at $30{ }^{\circ} \mathrm{C}$ in dark and soil moisture was maintained at $40 \%$ (w/w of dry weight of soil). Soil samples were collected and extracted with acetonitrile- acetone at regular time interval as per method described by Mohpatra et al. (2010). A representative $50 \mathrm{~g}$ soil sample was extracted with $100 \mathrm{~mL}$ 7:3 (v/v) acetonitrile-acetone followed by its filtration under vacuum through a Buchner funnel. The combined extracts were collected after washing the container and the filter cakes twice with $100 \mathrm{~mL}$ of the solvent mixture. The acetonitrile-acetone fraction was concentrated and the residues obtained were diluted with $30 \mathrm{~mL}$ saturated sodium chloride solution. The contents were par-

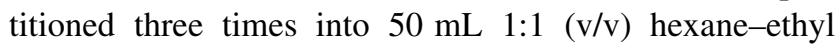
acetate. The hexane-ethyl acetate fraction was concentrated to $5 \mathrm{~mL}$ by drying over anhydrous sodium sulphate. The extracts were filtered by passing through column with florosil as the adsorbent and analyzed by GLC.

Analytical method was validated by fortification of fipronil and all its metabolites in soil at the rate of $0.01,0.1$ and $1.0 \mathrm{mg} \mathrm{kg}^{-1}$. Recovery of fipronil and its metabolites were in the range of 94-98\%. Fipronil and its metabolites was analyzed using GLC Hewlett-Packard 5890 series II equipped with electron capture detector (ECD) U.H.P. grade. A capillary column, equity 5 was used and flow rate of Helium as a carrier gas was maintained at $1 \mathrm{~mL} \mathrm{~min}{ }^{-1}$. Following temperature programming was used: an oven was initially held at $100{ }^{\circ} \mathrm{C}$ for $0.5 \mathrm{~min}$, and then for $3 \mathrm{~min}$. Ion source and interface temperature were 230 and $260{ }^{\circ} \mathrm{C}$, respectively. Standards of fipronil and all its metabolites were run under identical operating conditions for the identification and quantification of compounds formed after degradation.

\section{Data analysis}

All of the experiments were performed in triplicates. The data were evaluated using analysis of variance (ANOVA) and the statistical significance of difference among the treatments was analyzed by SPSS statistical package (Statgraphics Plus V. 11). Means with significant differences were expressed at 0.05 probability levels.

\section{Results and discussion}

\section{Isolation and identification of fipronil degrading strain}

An indigenous bacterial strain capable of utilizing fipronil as a sole carbon and energy source was eventually isolated from the fipronil contaminated soil. Strain S1 was a gram negative, rod shaped bacterium. Strain S1 showed positive enzymatic reactions for $\mathrm{H}_{2} \mathrm{~S}$ production, oxidase, catalase with assimilation of lysine, ornithine, D-glucose, D-fructose, mannose and arabinose (Table 1). Sugar assimilation efficiency of Stenotrophomonas sp. has been reported by 
Table 1 Biochemical characteristics for fipronil degrading soil isolate $\mathrm{S} 1$

\begin{tabular}{ll}
\hline Characteristics & S1 \\
\hline Morphological & Pale yellow \\
Colony color & - \\
Gram nature & Rod \\
Cell morphology & \\
Biochemical test & + \\
$\mathrm{H}_{2}$ S production & - \\
Urea & + \\
Oxidase & + \\
Catalase & - \\
Phenylalanine deamination & - \\
Nitrate reduction & + \\
Lysine & + \\
Ornithine & \\
Utilization of C-Sources & + \\
D-Glucose & + \\
D-Fructose & + \\
Mannose & + \\
Adonitol & - \\
Arabinose & - \\
Citrate & + \\
Lactose & \\
Sorbitol & + \\
\hline
\end{tabular}

+ positive, - negative
Uniyal et al. (2013). Results of 16SrRNA sequencing using universal primers with data bank sequences (GenBank) indicated $100 \%$ similarity of strain S1 with Stenotrophomonas acidaminiphila. The resultant phylogenetic tree depicts the phylogenetic relationship of this isolate with already reported species in GenBank (Fig. 1). The $16 \mathrm{~S}$ rRNA gene sequence of strain S1 was deposited in the GenBank nucleotide sequence databases under accession no. KJ396942. Growth profile of bacterial isolate S1 showed most effective growth of bacterial isolate within 8 days of incubation; correspondingly, fipronil concentration sharply declined within same time period and finally degraded up to $70.2 \%$ of the initial concentration after 14 days of incubation period (Fig. 2). No change in OD 600 was observed for non-inoculated control within 14 days of incubation period. Results indicated that isolated strain can efficiently utilize fipronil as a sole carbon and energy source. Several bacterial species such as Paracoccus sp. (Kumar et al. 2012), B. firmus (Mandal et al. 2013) and B. thuringiensis (Mandal et al. 2014) are reported to utilize fipronil as a sole source of carbon and energy (Table 2).

\section{Optimization of the fipronil-degrading conditions by strain $\mathrm{S1}$}

The optimum ranges of three significant factors (temperature $25-45{ }^{\circ} \mathrm{C}$; $\mathrm{pH} 5-10$; biomass amount $0.1-0.25 \mathrm{~g} \mathrm{~L}^{-1}$ ) were tested for fipronil degradation by single-factorial
Fig. 1 Phylogenetic tree of strain $\mathrm{S} 1$ constructed by the neighbor-joining method based on nucleotide sequences of the partial $16 S$ rRNA genes. The number at the nodes represents percentage bootstrap value of 1000 replicates

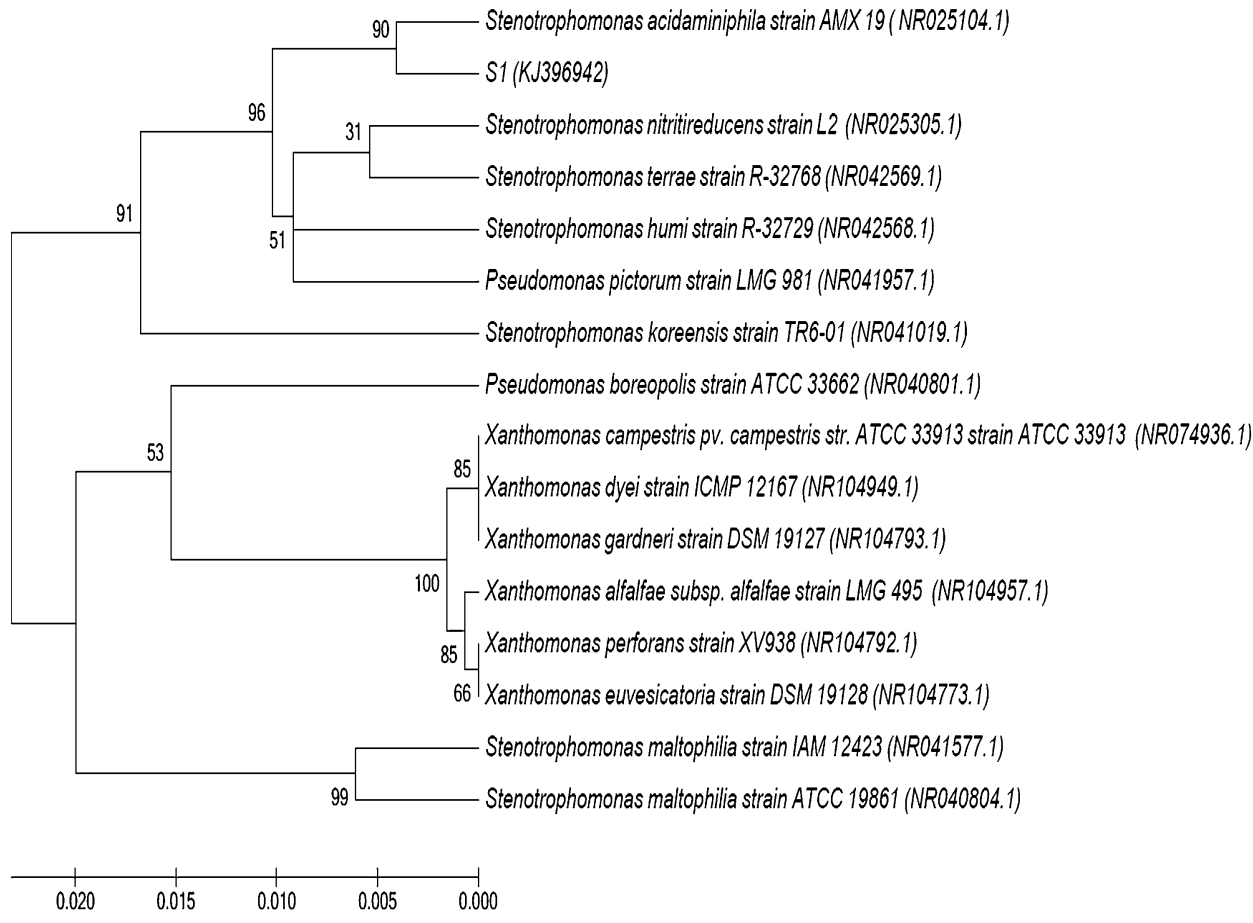


Fig. 2 Growth of bacterial strain S1 in Dorn's broth medium supplemented with fipronil $\left(25 \mathrm{mg} \mathrm{L}^{-1}\right)$ as a sole carbon source. Error bars represent the standard deviation within $5 \%$ of the mean

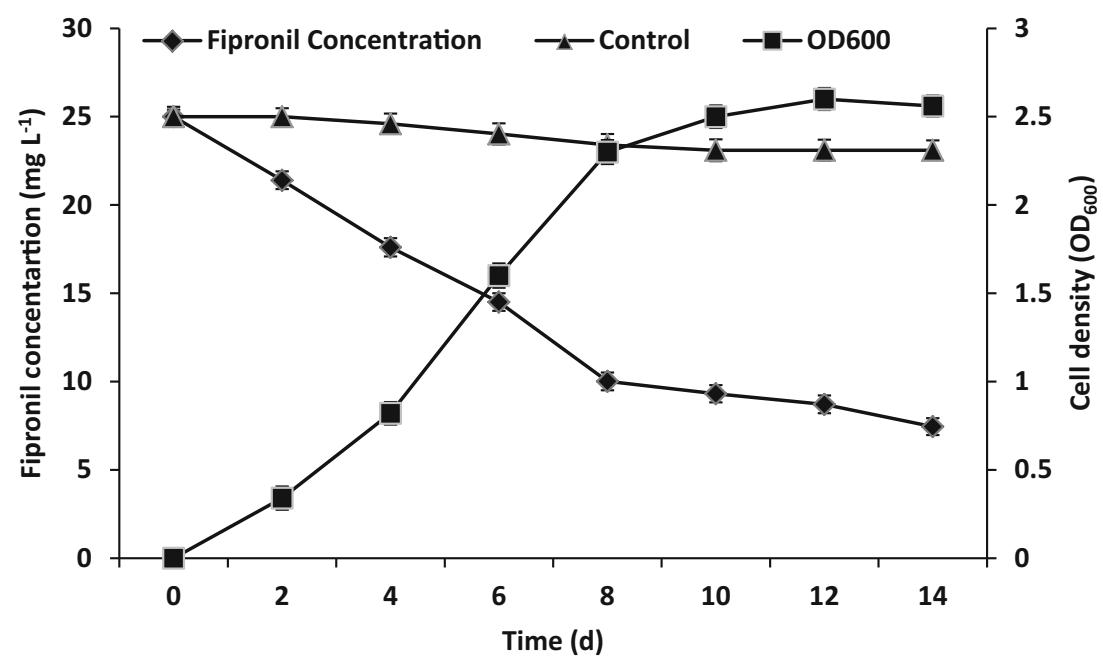

Table 2 Fipronil degradation by bacteria in soil

\begin{tabular}{lll}
\hline Bacteria employed & Initial dose & $\begin{array}{l}\text { Time taken to achieve } \\
\text { fipronil degradation below } \\
\text { detectable limit (days) }\end{array}$
\end{tabular}

\begin{tabular}{llll}
\hline Stenotrophomonas acidaminiphila & $50.0 \mathrm{mg} \mathrm{kg}^{-1}$ & 90 & Present study \\
Bacillus firmus & $1.5 \mathrm{mg} \mathrm{kg}^{-1}$ & 35 & Mandal et al. (2014) \\
Bacillus thuringiensis & $1.5 \mathrm{mg} \mathrm{kg}^{-1}$ & 35 & Mandal et al. (2013) \\
Paracoccus sp. & $80.0 \mathrm{\mu g} \mathrm{kg}^{-1}$ & 60 & Kumar et al. (2012) \\
\hline
\end{tabular}

experiments. The experimental and predicted values of degradation by a complete three-factor-three level factorial experimental design, with three replications at the central points, are represented in Table 3. The quadratic model was employed for response of fipronil degradation. Subsequently the obtained results were fitted with the secondorder polynomial equation (Eq. 2):

$$
\begin{aligned}
Y= & -634.642+23.375 X_{1}+83.528 X_{2}+107.652 X_{3} \\
& -0.371 X_{1} X_{2}-1.22 X_{1} X_{3}-24 X_{2} X_{3}-0.300 X_{1}^{2} \\
& -4.634 X_{2}^{2}+646.519 X_{3}^{2}
\end{aligned}
$$

$Y$ is the predicted value of fipronil degraded by strain $\mathrm{S} 1$; $X_{1}, X_{2}$ and $X_{3}$ are the coded values of the temperature, media $\mathrm{pH}$ and inocula biomass, respectively.

The significant $F$-value (121.46) and the non-significant lack-of fit $(0.16)$ value through the analysis of variance of the data imply that the quadratic model is highly significant (Table 4). Thus, the quadratic polynomial model, used in the present experiment adequately represented the actual relationship between response and variables. The $P$ value serves as a tool for checking the significance of each of the coefficients, which also indicates the interaction strength of each parameter (Acikel et al. 2010). $P$ values pointed that the linear and square terms of temperature $\left(X_{1}\right)$ and $\mathrm{pH}\left(X_{2}\right)$ values were highly significant $(p<0.01)$. However, the interaction effects of linear and square terms of inocula biomass amount $\left(X_{3}\right)$ showed insignificant effects $(p>0.05)$ on the fipronil degradation by strain $\mathrm{S} 1$. The coefficient of determination $\left(R^{2}\right)$ of the model was 0.995 , which further indicated a good agreement between the experimental and predicted values for fipronil degradation. The value of the coefficient of variation $(\mathrm{CV}=5.00 \%)$, which also revealed adequacy of the model. Using RSM, the three-dimensional response surface plots of fipronil degradation were presented as a function of independent variables (Fig. 3). An elliptical response surface was observed with maximum response near centre point indicating that the interaction between corresponding variables is significant. At higher temperature and $\mathrm{pH}$, fipronil degradation was reduced that might be due to the lowering of enzymatic activities at respective conditions.

Previous studies have shown that the application of statistical experimental design techniques in complex processes can result in enhanced yields and allow a rapid and economical determination of the optimum conditions with reduced experiments and minimal resources (Ghevariya et al. 2011; Chen et al. 2013). In the present study, a quadratic polynomial model was effectively used for the optimization of fipronil degradation by strain S1. The optimum values of temperature, $\mathrm{pH}$ and inocula biomass 
Table 3 Box-Behnken design matrix along with the experimental and predicted values of fipronil degradation

\begin{tabular}{llllll}
\hline & Factor 1 & Factor 2 & Factor 3 & Predicted response & Experimental response \\
\hline Run & A:X1 & B:X2 & C:X3 & R1 & R2 \\
& ${ }^{\circ} \mathrm{C}$ & $\mathrm{pH}$ & $\mathrm{g} / 1$ & Percent degradation & 51.20 \\
1 & 35 & 10.0 & 0.100 & 46.90 & 38.14 \\
2 & 45 & 5.0 & 0.175 & 37.30 & 57.50 \\
3 & 45 & 7.5 & 0.250 & 56.50 & 80.17 \\
4 & 35 & 5.0 & 0.250 & 78.80 & 44.29 \\
5 & 45 & 7.5 & 0.100 & 44.16 & 57.96 \\
6 & 35 & 10.0 & 0.250 & 57.10 & 83.88 \\
7 & 35 & 7.5 & 0.175 & 82.70 & 85.21 \\
8 & 35 & 7.5 & 0.175 & 83.00 & 86.14 \\
9 & 35 & 7.5 & 0.175 & 85.30 & 31.76 \\
10 & 25 & 5.0 & 0.175 & 30.80 & 56.56 \\
11 & 25 & 7.5 & 0.100 & 56.20 & 31.50 \\
12 & 25 & 10.0 & 0.175 & 30.60 & 73.89 \\
13 & 25 & 7.5 & 0.250 & 72.20 & 52.30 \\
14 & 35 & 5.0 & 0.100 & 50.60 & 0 \\
\hline 15 & 45 & 10.0 & 0.175 & 0 & \\
\hline
\end{tabular}

Table 4 ANOVA for response surface quadratic model for fipronil degradation

\begin{tabular}{|c|c|c|c|c|c|c|}
\hline Source & Sum of squares & df & Mean square & $F$ value & $P$ value Prob. $>F$ & Remarks \\
\hline Model & 8013.8800 & 9 & 890.4311 & 121.4625 & $<0.0001$ & Significant \\
\hline A-X1 & 335.9232 & 1 & 335.9232 & 45.8228 & 0.0011 & \\
\hline $\mathrm{B}-\mathrm{X} 2$ & 494.5513 & 1 & 494.5513 & 67.4610 & 0.0004 & \\
\hline $\mathrm{C}-\mathrm{X} 3$ & 556.7785 & 1 & 556.7785 & 75.9494 & 0.0003 & \\
\hline $\mathrm{AB}$ & 344.1025 & 1 & 344.1025 & 46.9386 & 0.0010 & \\
\hline $\mathrm{AC}$ & 3.3489 & 1 & 3.3489 & 0.45682 & 0.5291 & \\
\hline $\mathrm{BC}$ & 81.0000 & 1 & 81.0000 & 11.0491 & 0.0209 & \\
\hline$A^{2}$ & 3331.5750 & 1 & 3331.5750 & 454.4556 & $<0.0001$ & \\
\hline $\mathrm{B}^{2}$ & 3095.2450 & 1 & 3095.2450 & 422.2182 & $<0.0001$ & \\
\hline $\mathrm{C}^{2}$ & 48.8320 & 1 & 48.8320 & 6.6611 & 0.0494 & \\
\hline Residual & 36.6546 & 5 & 7.3309 & & & \\
\hline Lack of fit & 32.6079 & 3 & 10.8693 & 5.3720 & 0.1609 & Not significant \\
\hline Pure error & 4.0467 & 2 & 2.0233 & & & \\
\hline Cor total & 8050.5350 & 14 & & & & \\
\hline
\end{tabular}

$d f$ degrees of freedom

for maximum fipronil degradation $(85.30 \%)$ were predicted to be $35^{\circ} \mathrm{C}, 7.5$ and $0.175 \mathrm{~g} \mathrm{~L}^{-1}$ from the model. The optimum combinations of variables were validated by conducting experiments and the fipronil degradation of $86.14 \%$ was recorded, which was close to the predicted maximum value.

The metabolites formed as a result of fipronil degradation were analyzed by GLC. Metabolites formed were identified as fipronil sulfide, sulfone and amide. The retention time of fipronil, fipronil sulfide, fipronil sulfone, fipronil amide was found to be $6.36,6.14,8.53$ and $11.3 \mathrm{~min}$, respectively. Analyzing the new metabolic products, a novel fipronil degradation pathway for S. acidaminiphila was proposed (Fig. 4). The result showed that fipronil was degraded to form sulfone, sulfide and amide by oxidation, reduction and hydrolysis reaction. Although biodegradation of fipronil has been studied (Mandal et al. 2014; Mandal et al. 2013), fipronil degradation pathway by any bacteria is still not reported. 
(a)

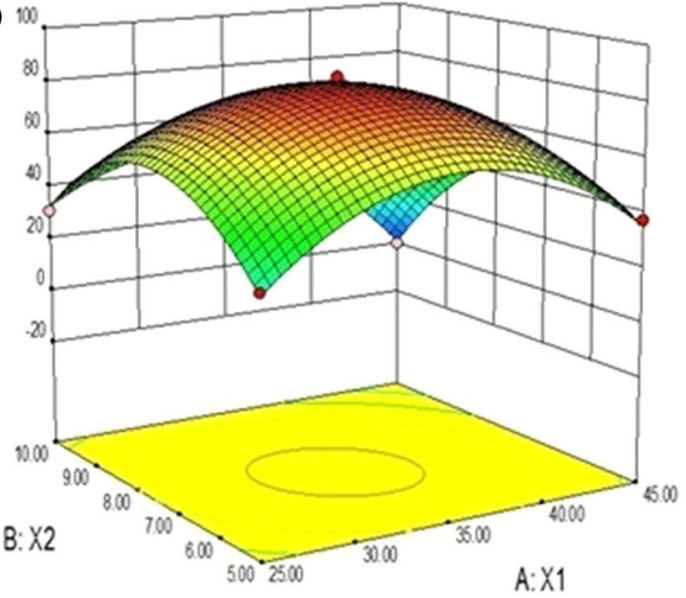

(c)

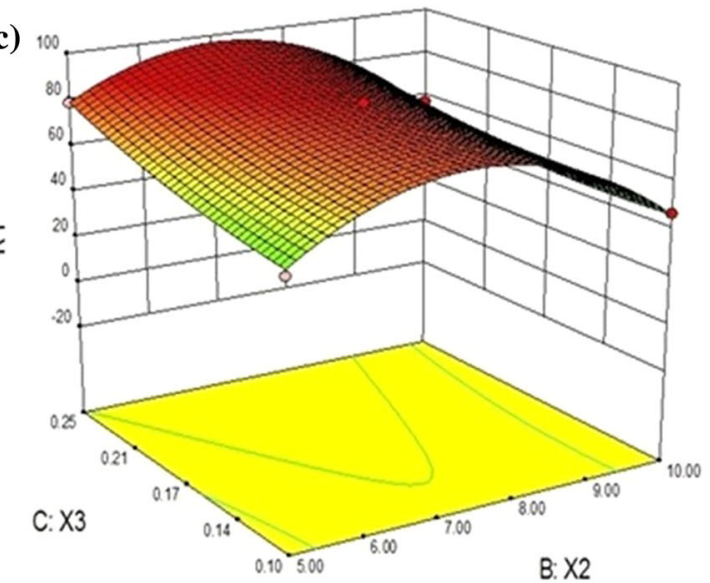

(b)

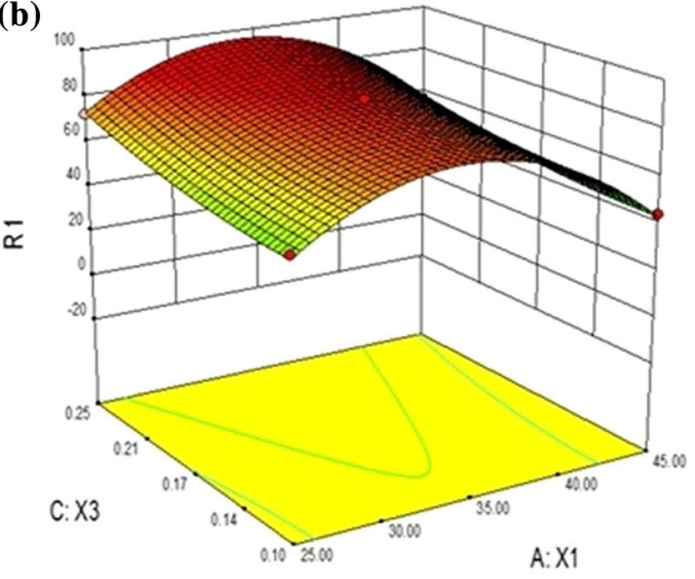

Fig. 3 Response surface curves described by the model $Y$, which represents the effect of interactions between a temperature $\left(X_{1}\right)$ and $\mathrm{pH}\left(X_{2}\right)$ b total biomass inocula $\left(X_{3}\right)$ and temperature $\left(X_{1}\right)$ c total biomass inocula $(X 3)$ and $\mathrm{pH}(X 2)$ on fipronil degradation

Fig. 4 Metabolic pathway for fipronil degradation by $S$. acidaminiphila

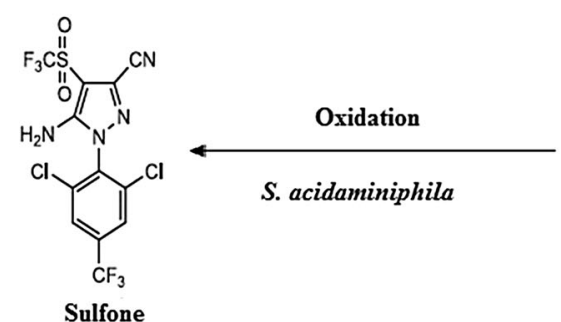

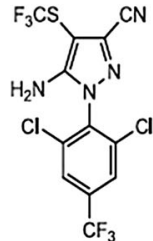

Sulfide

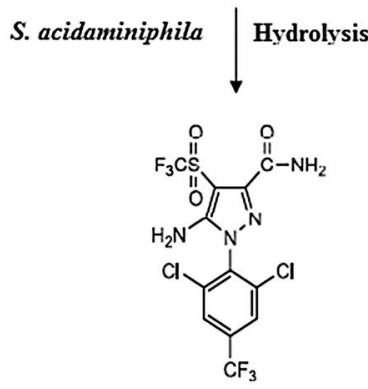

Amide 


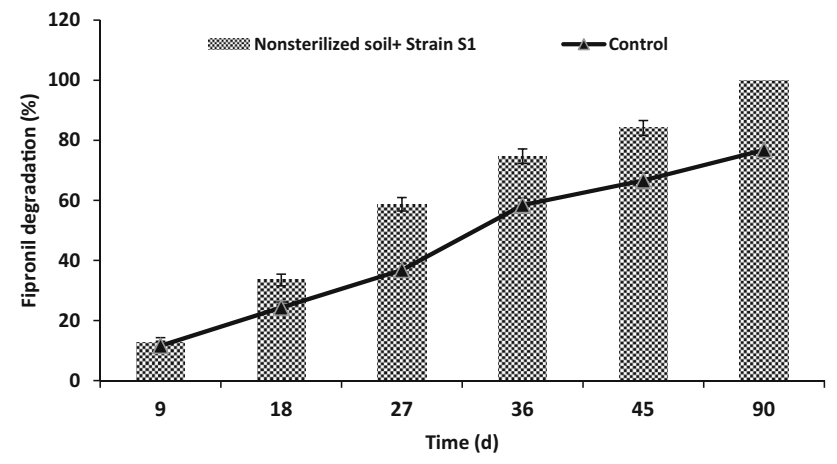

Fig. 5 Degradation dynamics of fipronil in non-sterilized soils. Error bars represent the standard deviation within $5 \%$ of the mean

\section{Persistence of fipronil in sandy loam soil amended with $S$. acidaminiphila}

Sandy loam soil fortified with $50 \mathrm{mg} \mathrm{kg}{ }^{-1}$ of fipronil was analyzed at $9,18,27,36,45$ and 90 days of time period. Degradation study of fipronil showed significantly greater fipronil degradation $(84.12 \%)$ after 45 days of time interval in non-sterilized treatment inoculated with $S$. acidaminiphila, however, only $66.64 \%$ fipronil degradation was observed in non-sterilized control condition within the same time interval (Fig. 5). No fipronil residues were detected in non-sterilized treatment after 90 days of time period. Masutti and Mermut (2007) observed significant decline in fipronil levels from 0.689 to $0.399 \mu \mathrm{g} \mathrm{g}^{-1}$ under non-sterile condition within 120 days of incubation period. Similarly, the residues of fipronil were found to persist only up to 10 days in soils fortified with fipronil at the rate of $20 \mu \mathrm{g} \mathrm{kg}^{-1}$ and amended with Paracoccus sp. while in the soils fortified at the rate of $80 \mu \mathrm{g} \mathrm{kg}^{-1}$ fipronil, residues persisted up to 20, 30 and 30 days in loamy sand, sandy loam and clay loam, respectively (Kumar et al. 2012).

The maximum residues of metabolites were found to be 4.76 and $1.98 \mathrm{mg} \mathrm{kg}^{-1}$ in soil collected at 7 days, which were further degraded to 0.65 and $1.02 \mathrm{mg} \mathrm{kg}^{-1}$ after 45 days in non-sterilized control and non-sterilized treatment, respectively (Fig. 6). Fipronil residues were degraded to below the quantifiable limit of $0.01 \mathrm{mg} \mathrm{kg}^{-1}$, in non-sterilized treatment after 90 days of time period. In non-sterilized control, fipronil residues were still present after 90 days of time period with value of $0.66,0.25$ and $0.11 \mathrm{mg} \mathrm{kg}^{-1}$ for fipronil sulfone, sulfide and amide, respectively. Mandal et al. (2013) reported quicker degradation of fipronil in B. thuringiensis inoculated soil. The residues of fipronil and its metabolites were degraded to $0.40 \mathrm{mg} \mathrm{kg}^{-1}$ in 21 days after the application of fipronil at the rate of $1.50 \mathrm{mg} \mathrm{kg}^{-1}$. Mandal et al. (2014) observed $0.48 \mathrm{mg} \mathrm{kg}^{-1}$ residues of fipronil and its metabolites at

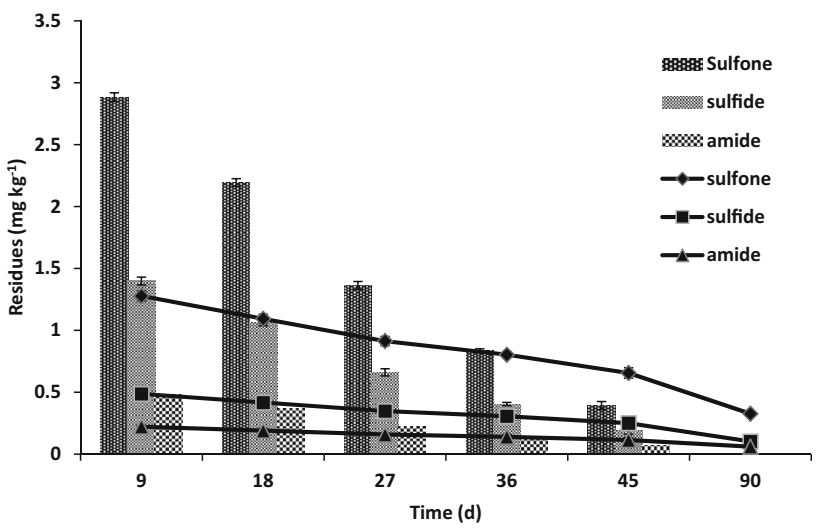

Fig. 6 Residues of metabolites $\left(\mathrm{mg} \mathrm{kg}^{-1}\right)$ of fipronil degradation in non-sterilized soil inoculated with strain $\mathrm{S} 1$ (bar) and non-sterilized control (line) fortified with $50 \mathrm{mg} \mathrm{kg}^{-1}$ fipronil. Error bars represent the standard deviation within $5 \%$ of the mean

28 days after application of fipronil at the rate of $1.50 \mathrm{mg} \mathrm{kg}^{-1}$, in soil inoculated with $B$. firmus.

Fipronil sulfone was formed as a major metabolite followed by sulfide and amide (Fig. 5). Ying and Kookana (2002) reported that soil microorganisms accelerated the degradation of fipronil to sulfide and sulfone metabolites while studying fipronil degradation in laboratory and field soil. Masutti and Mermut (2007) found that sulfone derivative (an oxidation product) was the predominant metabolite, whereas the sulfide (a reduction product) derivative was the second most common metabolite found under non-sterile conditions. Sulfone and sulfide concentration increased up to 5 days of incubation, then decreased significantly after 7.5 days. Sulfone values were $34 \%$ lower, while sulfide levels were $31 \%$ higher than those found for the initial 5 days period after 30 days of time period.

\section{Degradation kinetics of fipronil residues}

Fipronil degradation rate in two different conditions was found to follow a pseudo first-order kinetic reaction.

${ }_{\ln } \mathrm{C}_{0} / \mathrm{C}=-K\left(t-t_{0}\right)$

where $\mathrm{C}_{0}$ is the maximum concentration of fipronil ( $\mathrm{mg} \mathrm{kg}^{-1}$ in soil); $\mathrm{C}$ is the concentration of fipronil $\left(\mathrm{mg} \mathrm{kg}^{-1}\right)$ in soil at the time of $t ; t$ is the treatment times in days; $t_{0}$ is the treatment time of maximum concentration in days; $k$ is fipronil degradation rate constants $\left(\right.$ days $\left.^{-1}\right)$. The degradation rate constant $(k)$ values were calculated from the linear equation obtained from regression plots of $\ln \left(\mathrm{C}_{0} /\right.$ C) versus time $(t)$. Result suggested that the fipronil in nonsterilized treatment inoculated with $S$. acidaminiphila degraded faster (equation $C=0.77 \mathrm{e}^{-0.046 \mathrm{t}} ; R^{2}=0.98$; $k=0.046 ; \mathrm{t}_{1 / 2}=15.09$ days) than non-sterilized control 
(equation $C=0.42 \mathrm{e}^{-0.027} ; R^{2}=0.94 ; k=0.027 ; \mathrm{t}_{1 / 2}$ $=25.67$ days). The difference in $k$ values and half-life observed in both conditions may be attributed to the fipronil degradation potential of isolated S. acidaminiphila, which resulted in enhanced degradation. The microbial degradation of fipronil in soils was studied by Zhu et al. (2004) who found that the $t_{1 / 2}$ of fipronil in non-sterile clay loam was 9.72 and 8.78 days at 25 and $35{ }^{\circ} \mathrm{C}$, respectively. Lin et al. (2008) observed that the degradation of fipronil in sediments generally followed exponential decay kinetics and the first-order half-lives of fipronil were only 4.6-18.5 days in anaerobic sediments. Chopra et al. (2010) reported that the dissipation of fipronil residues in soil followed first order kinetics with half life values of 23.35 and 24.31 days at 56 and $112 \mathrm{~g}$ a.i. ha ${ }^{-1}$ doses.

\section{Conclusion}

The present study clearly demonstrated the ability of $S$. acidaminiphila to degrade and utilize fipronil as a sole source of carbon and energy. To authors' knowledge, this is the first report of fipronil degradation by $S$. acidaminiphila. Under optimum conditions, $86.14 \%$ of fipronil could be degraded after 14 days of cultivation in Dorn's broth media amended with $25 \mathrm{mg} \mathrm{L}^{-1}$ fipronil. Kinetics and fipronil degradation study in non-sterilized soils indicated potential use of $S$. acidaminiphila for bioremediation of fipronil contaminated soil. Inoculation of S. acidaminiphila also resulted in complete degradation of toxic metabolites. These findings will certainly provide new insights in the indication of useful ways for bioremediation of fipronil-contaminated environment.

Acknowledgements Laboratory facilities of G.B. Pant University of Agriculture \& Technology, Pantnagar and Inspire Fellowship to Shivani Uniyal from Department of Science and Technology, New Delhi are thankfully acknowledged.

\section{Compliance with ethical standards}

Conflict of interest The authors declare that they have no conflict of interest.

Open Access This article is distributed under the terms of the Creative Commons Attribution 4.0 International License (http:// creativecommons.org/licenses/by/4.0/), which permits unrestricted use, distribution, and reproduction in any medium, provided you give appropriate credit to the original author(s) and the source, provide a link to the Creative Commons license, and indicate if changes were made.

\section{References}

Aajoud A, Ravanel P, Tissut M (2003) Fipronil metabolism and dissipation in a simplified aquatic ecosystem. J Agric Food Chem 51:1347-1352
Acikel U, Ersana M, Sag Acikel Y (2010) Optimization of critical medium components using response surface methodology for lipase production by Rhizopus delemar. Food Bioprod Process 88:31-39

Chanton PF, Ravanel P, Tissut M, Meyran JC (2001) Toxicity and bioaccumulation of fipronil in the nontarget arthropodan fauna associated with subalpine mosquito breeding. Ecotoxicol Environ Saf 52:8-12

Chen H, He X, Rong X, Chen W, Cai P, Liang W, Li S, Huang Q (2009) Adsorption and biodegradation of carbaryl on montmorillonite, kaolinite and goethite. Applied Clay Sci 46:102-108

Chen S, Dong YH, Chang C, Deng Y, Zhang XF, Zhong G, Song H, $\mathrm{Hu}$ M, Zhang LH (2013) Characterization of a novel cyfluthrindegrading bacterial strain Brevibacterium aureum and its biochemical degradation pathway. Bioresour Technol 132:16-23

Chevillard A, Coussy HA, Guillard V, Gontard N, Gastaldi E (2012) Investigating the biodegradation pattern of an ecofriendly pesticide delivery system based on wheat gluten and organically modified montmorillonites. Polym Degrad Stab 97:2060-2068

Chopra I, Chauhan R, Kumari B, Dahiya KK (2010) Fate of fipronil in cotton and soil under tropical climatic conditions. Bull Environ Contam Toxicol 86:242-245

Ecobichon DJ (1996) Toxic effects of pesticides. In: Klaassen CD, Doull J (eds) Casarett and Doull's Toxicology: the basic science of Poisons, 5th edn. MacMillan, New York, pp 643-689

Ghevariya CM, Bhatt JK, Dave BP (2011) Enhanced chrysene degradation by halotolerant Achromobacter xylosoxidans using response surface methodology. Bioresour Technol 102:9668-9674

Gunasekara AS, Troung T, Goh KS, Spurlock F, Tjeerdema R (2007) Environmental fate and toxicology of fipronil. J Pest Sci 32(3):189-199

Karpouzas DG, Ntougias S, Iskidou E, Rousidou C, Papadopoulou KK, Zervakis G, Ehaliotis C (2010) Olive mill wastewater affects the structure of soil bacterial communities. Appl Soil Ecol 45:101-111

Kumar R, Singh B, Gupta VK (2012) Biodegradation of fipronil by Paracoccus sp. in different types of soil. Bull Environ Contam Toxicol 88:781-787

Li C, Zhang J, Wu ZG, Cao L, Yan X, Li SP (2012) Biodegradation of Buprofezin by Rhodococcus sp. Strain YL-1 isolated from rice field soil. J Agric Food Chem 60:2531-2537

Lin K, Haver D, Oki L, Gan J (2008) Transformation and sorption of fipronil in urban stream sediments. J Agric Food Chem 56:8594-8600

Mandal K, Singh B, Jariyal M, Gupta VK (2013) Microbial degradation of fipronil by Bacillus thuringiensis. Ecotoxicol Environ Saf 93:87-92

Mandal K, Singh B, Jariyal M, Gupta VK (2014) Bioremediation of fipronil by a Bacillus firmus isolate from soil. Chemosphere 101:55-60

Masutti CSM, Mermut AR (2007) Degradation of fipronil under laboratory conditions in a tropical soil from Sirinhaem Pernambuco. Braz J Environ Sci Health B 42:33-43

Mohapatra S, Deepa M, Jagdish GK, Rashmi N, Kumar S, Prakash GS (2010) Fate of fipronil and its metabolites in/on grape leaves, berries and soil under semi arid tropical climatic conditions. Bull Environ Contam Toxicol 84:587-591

Paliwal R, Uniyal S, Rai JPN (2015a) Evaluating the potential of immobilized bacterial consortium for black liquor decolorization and delignification. Environ Sci Pollut Res 22(9):6842-6853

Paliwal R, Uniyal S, Verma M, Kumar A, Rai JPN (2015) Process optimization for biodegradation of black liquor by immobilized novel bacterial consortium. Desalination Water Treat. doi: 10. 1080/19443994.2015.1092892

Pan-UK (2003) Current pesticide spectrum, global use and major concerns. http://www.pan-uk.org/brie.ng/sidafil/chap1.htm. Accessed 14 Feb 2008

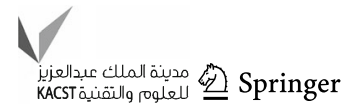


Phugare SS, Jadhav JP (2014) Biodegradation of acetamiprid by isolated bacterial strain Rhodococcus sp. $\mathrm{BCH} 2$ and toxicological analysis of its metabolites in silkworm (Bombax mori). CLEAN-Soil, Air, Water. doi:10.1002/clen.201200563

Prakasham RS, Rao CS, Rao RS, Rajesham S, Sarma PN (2005) Optimization of alkaline protease production by Bacillus $\mathrm{sp}$ using Taguchi methodology. Appl Biochem Biotechnol 120:133-144

Ramanathan MP, Lalithakumari D (1999) Complete mineralization of methylparathion by Pseudomonas sp. A3. Appl Biochem Biotechnol 80(1):1-12

Sidhu PK, Dhanjal NIK, Cameotra SS, Sud D (2014) Persistence and biodegradation of monocrotophos using soil microbes. Desalination Water Treat. doi:10.1080/19443994.2014.899516

Tingle CC, Rother JA, Dewhust CF, Lauer S, King WJ (2003) Fipronil: environmental fate, ecotoxicology, and human health concerns. Rev Environ Contam Toxicol 176:1-66
Tomlin CDS (2000) The pesticide manual. The British Crop Protection Council, Surrey, pp 413-415

Uniyal S, Rawat M, Rai JPN (2013) Cadmium biosorption by Stenotrophomonas humi and Micrococcus luteus: kinetics, equilibrium and thermodynamic studies. Desalination and Water Treat 51:1-13

Wang G, Yue W, Liu Y, Li F, Xiong M, Zhang H (2013) Biodegradation of the neonicotinoid insecticide acetamiprid by bacterium Pigmentiphaga sp. strain AAP-1 isolated from soil. Bioresour Technol 138:359-368

Ware GW (2000) An introduction to insecticides. The pesticide book. Thomson, Fresno, p 69

Ying GG, Kookana R (2002) Laboratory and field studies on the degradation of fipronil in a soil. Aust J Soil Res 40:1095-1102

Zhu G, Wu H, Guo J, Kimaro FME (2004) Microbial degradation of fipronil in clay loam soil. Water Air Soil Pollut 153:35-44 